\title{
A IMPORTÂNCIA DAS VIRTUDES DA PRUDÊNCIA E DA JUSTIÇA NA ATIVIDADE DO JURISTA
}

\author{
Daniel \\ Nunes \\ Pêcego ${ }^{1}$ \\ Carla dos Santos \\ Brasil $^{2}$
}

\begin{abstract}
Resumo
O presente estudo discorreu sobre a atividade do jurista de acordo com o Realismo Jurídico Clássico, que se baseia na filosofia aristotélico-tomista. Ele tem o objetivo de demonstrar a importância da prudência (reta razão do agir) e da justiça (vontade constante e perpétua de dar a cada um o que lhe é devido) - ambas virtudes cardeais - ao executar esta função. A fim de alcançar o objetivo pretendido, foi realizada pesquisa bibliográfica em doutrinas de filosofia moral e filosofia do Direito. A conclusão alcançada é a de que, além de possuir saber jurídico, o jurista necessita aprimorar-se moralmente.
\end{abstract}

Palavras-chave: Jurista. Prudência. Justiça.

\section{INTRODUÇÃO}

Até o início da Modernidade, a doutrina mais largamente utilizada para definir a justiça e, consequentemente, explicar a atividade do jurista, era a de base clássica, notadamente aristotélica, com os desenvolvimentos posteriores dados pelos juristas romanos e pela Escolástica medieval. É o que poderia ser chamado de Realismo Jurídico Clássico. Como afirmado, essa doutrina teve suas bases desenvolvidas na Grécia Antiga por Aristóteles, foi aperfeiçoada pelo Direito Romano, até atingir sua feição mais bem-acabada com Tomás de Aquino.

$\mathrm{Na}$ percepção da psicologia aristotélico-tomista, na qual está assente o Realismo Jurídico Clássico, as virtudes morais têm fundamental importância para o agir humano, visto que o orientam em direção ao bem. Assim, nessa concepção, para que o jurista realize seu

\footnotetext{
${ }^{1}$ Doutor em Direito pelo Programa de Pós-Graduação em Direito da Universidade do Estado do Rio de Janeiro (UERJ). Professor Adjunto da Faculdade de Direito da UERJ. E-mail: carlabrasil-rj@ hotmail.com

2 Bacharel em Direito pela Universidade Federal Rural do Rio de Janeiro (UFRRJ). E-mail: dpecego@hotmail.com vol.09, n. 03, Rio de Janeiro, 2016. pp. 
ofício é necessário que ele seja aperfeiçoado em suas potências pelas virtudes, em especial pela prudência e pela justiça.

Nesse contexto, o presente trabalho tem como objetivo principal mostrar, sob a ótica do Realismo Jurídico Clássico, a importância das virtudes morais ao jurista, principalmente a prudência (reta razão do agir) e a justiça (vontade constante e perpétua de dar a cada um o seu direito), no exercício de sua atividade.

Importante destacar que neste estudo são considerados juristas os juízes, os advogados, os consultores e assessores jurídicos, os tabeliães, e aqueles que exercem atividades similares. Todavia, nos debruçamos especificamente sobre aqueles que intervêm em um julgamento ou que se dedicam a descobrir o direito atribuído aos indivíduos, dentre os quais citamos os juízes, os advogados e os doutrinadores.

A importância desse estudo reside em demonstrar que, para que um jurista exerça bem sua função, não é suficiente que ele detenha apenas um grande conhecimento técnico-jurídico, sendo igualmente necessário que, para além disso, ele se aperfeiçoe moralmente através das virtudes da prudência e da justiça.

\section{A PSICOLOGiA ARISTOTÉlico-TOMista e AS VIRTUDES}

De acordo com a psicologia aristotélico-tomista, "o ser vivente apresenta uma série de operações que correspondem a uma série de faculdades da alma, acidentais do gênero qualidade em relação à alma em si” (PÊCEGO, 2008a, p. 172). Nessa concepção, a alma racional possui muitas capacidades, que são denominadas potências da alma. Segundo Faitanin (s/d a), por potência entende-se "o princípio da ação, do agir e do operar (STh.I-II, q 55, a2, c). As potências da alma são, pois, as capacidades que a alma racional [possui] para, por meio delas, atingir a perfeição de sua própria natureza".

A alma humana possui três potências principais: a vegetativa, a sensitiva e a intelectiva. A primeira delas é aquela responsável pela nutrição, crescimento e geração do homem; a segunda se refere ao ato de perceber, e se utiliza dos sentidos externos (vista, audição, olfato, gosto e tato) e internos (percepção, imaginação, estimação e memória); finalmente, a terceira é uma "potência cognitiva da alma humana, por meio da qual a alma conhece algo de si, algo do que lhe rodeia e algo do que lhe transcende" (FAITANIN, s/d a).

A potência intelectual é a mais nobre potência da alma e tem como objeto a verdade (FAITANIN, s/d b). Ela é uma "potência cognitiva da alma humana, por meio da qual a alma conhece algo de si, algo do que lhe rodeia e algo do que lhe transcende" (FAITANIN, s/d a). Ela possui duas faculdades racionais: a inteligência (ou intelecto), pela qual "se conhecem as vol.09, n. 03, Rio de Janeiro, 2016. pp. 
coisas" (PÊCEGO, 2008a, p. 174) e a vontade, pela qual "se desejam as coisas que se conhece" (PÊCEGO, 2008a, p. 174). É através dessas faculdades que “o ser humano pode conhecer intelectualmente, captando (...) as coisas materiais, e desejar o bem conhecido e livremente escolhido" (PÊCEGO, 2008a, p. 174).

Incluída na potência intelectiva está a potência apetitiva, que consiste na "inclinação natural da alma racional, ou seja, da forma humana para aquilo que lhe é natural, daí o apetite natural" (FAITANIN, s/d a). Há na potência apetitiva dois apetites: o apetite da potência intelectiva, que é a vontade, e o apetite da potência sensitiva, chamado de apetite sensível. ${ }^{3}$ Este último, por sua vez, apresenta duas espécies: o apetite concupiscível (atração pelos bens desejáveis ou aversão pelos males indesejáveis) e o apetite irascível (atração pelos bens árduos ou fuga dos males difíceis de serem evitados). Assim, o apetite sensível está inserido na potência apetitiva, que, por sua vez, está incluída na potência intelectiva, de forma que o apetite sensível e suas espécies obedecem à razão, estando submetidos à vontade do sujeito.

O homem, ao realizar uma ação, é guiado pelas faculdades racionais da potência intelectual, quais sejam: a inteligência (ou razão, não se procedendo aqui a uma distinção entre ambos os conceitos) e a vontade. A primeira leva o homem a saber que atitude deve tomar; já a segunda o impulsiona a agir de acordo com o que a primeira determina. No entanto, apesar de o intelecto ser o responsável direto pela tomada de decisões do indivíduo, ele recebe influência das paixões ${ }^{4}$ e dos apetites sensíveis. Como ensina Faitanin (s/d b),

As paixões no homem afetam a sua inclinação a algum bem ou a aversão a algum mal. Por isso podem influenciar todo o rumo da formação do caráter e da instrução humana, pois elas podem determinar o voluntário, se o antecedem na inclinação ao bem ou na aversão ao mal.

Quando o conhecimento sensível reconhece algo como sendo bom, o homem naturalmente se inclina a desejar aquele bem e é impelido a querê-lo. No entanto, tal movimento, realizado pelas paixões, é feito de maneira espontânea e irreflexiva (ABBÀ, 2011), de forma que nem sempre o objeto das paixões é algo que, de fato, é bom. Nesse caso, cabe ao intelecto discernir se aquele objeto é mesmo bom ou ruim. Caso as paixões, que são moralmente neutras, sejam mal orientadas e antecedam a vontade na inclinação ao bem ou aversão ao mal, o indivíduo pode ser determinado por elas e realizar uma escolha ruim, ou seja, uma escolha que não esteja de acordo com a ordem estabelecida pela razão. Como ensina Tomás de Aquino (2012, p. 105), “o bem do homem, enquanto é homem, consiste que a razão

\footnotetext{
${ }^{3}$ Apetite sensível é "a inclinação ou tendência para as formas apreendidas pelo conhecimento sensível como bens" (PÊCEGO, 2008a, p. 174)

${ }^{4}$ Ou sentimentos, emoções, afetos.
} 
seja perfeita no conhecimento da verdade, e que os apetites inferiores sejam regulados conforme a regra da razão, pois o homem é homem porque é racional”.

Assim, para que o indivíduo realize uma boa escolha, ${ }^{5}$ é necessário que ele tenha suas potências orientadas pelas virtudes, que são qualidades habituais que aperfeiçoam o homem em suas capacidades (potências). Esses hábitos virtuosos são "formas impressas na alma, as quais a reparam, a retificam" (ABBÀ, 2011, p. 100).

Segundo Tomás de Aquino (2012), dentre as virtudes humanas há aquelas que são consideradas cardeais, sobre as quais se fundamentam as demais virtudes - a temperança, a fortaleza, a prudência e a justiça. Temperança é a virtude que aperfeiçoa o apetite concupiscível, a inclinação para o que é prazeroso, a deleitação do tato, sendo "toda moderação que refreie o apetite do homem pelos bens temporais" (AQUINO, 2012, p. 189); a fortaleza aperfeiçoa o apetite irascível, fazendo com que o indivíduo faça aquilo que é árduo, difícil, e é "toda firmeza da alma que assegura ao homem no bem contra o ataque de qualquer mal" (AQUINO, 2012, p. 189); a prudência aperfeiçoa a razão, a inteligência, e determina uma conduta orientando-a para um fim reto; e, finalmente, a justiça aperfeiçoa a vontade, consistindo no hábito pelo qual, com vontade constante e perpétua, se dá a cada um o seu direito (AQUINO, Summa Theologica, II-II, q. 58, a. 1), e, também, é toda retidão que ajusta os atos humanos (AQUINO, 2012, p. 189).

\section{A ATIVIDADE DO JURISTA}

A palavra jurista advém do termo latino ius ou jus, que quer dizer "direito" ou "justo". Assim, o jurista é aquele que se dedica a descobrir o que é justo nas relações sociais e cujo saber é a ciência do justo (HERVADA, 2006). Ele é o técnico da justiça (HERVADA, 2006). Tendo em vista que é a mesma coisa dizer que o "justo" é o seu de cada um, de acordo com a definição clássica de justiça ("justiça consiste na vontade constante e perpétua de dar a cada um o que é seu”), o jurista é aquele que se dedica a descobrir qual é o seu de cada indivíduo e é este o objeto de seu saber (HERVADA, 2006, p. 15).

Como ensina Hervada (2008, p. 53), o próprio do jurista é o cultivar a justiça, saber sobre o correto e o justo, discernir o justo do injusto, o lícito do ilícito. É o jurista quem realiza a iuris dictio, a declaração do direito, discernindo e pronunciando a sentença que contém o direito, o justo (HERVADA, 2008, p. 54). Deste modo, “o jurista diz, declara o direito: o juiz

\footnotetext{
${ }^{5}$ A ciência prática tomista explica que para que uma escolha humana (e a ação que dela decorre) seja boa, excelente e virtuosa, o fim visado pela intenção, o objeto que define a ação exterior e as circunstâncias relevantes da ação devem ser bons. (ABBÀ, 2011, p. 109)
} 
sentencia sobre de quem é o direito no caso concreto, o advogado alega o que entende ser o direito de seu cliente, o doutrinador manifesta o direito" (HERVADA, 2008, p. 54).

O ofício do jurista implica em uma ciência prática, pois se trata de um conhecimento sobre como fazer algo. O cerne de sua atividade é saber para fazer, saber para discernir o justo, saber dizer o direito de cada um. No entanto, é preciso ter em mente que o jurista não é o sujeito da atividade jurídica (HERVADA, 2008, p. 58), não é ele quem deve dar a cada um o seu. O jurista é aquele que descobre e diz o que deve ser dado a cada um, é quem discerne o justo. Ele é o possuidor de uma ciência ou capacidade de discernimento, e não o titular da referida atividade. Destarte, é ele quem sabe como as coisas estão repartidas, ${ }^{6}$ e não como fazer para reparti-las, visto que esta função é atribuída principalmente ao político (quando atua como legislador) (HERVADA, 2008, p. 61).

Para compreender o ofício do jurista, é necessário ter em mente que o direito, objeto da justiça, é atribuído a cada um pelas leis positivas ou pelas leis naturais, podendo ser, portanto, positivo ou natural. No primeiro caso, ele é fruto da "convenção e ou comum acordo, seja particular, seja por um meio público" (PÊCEGO, 2008b, p. 94), tanto por contrato, como por lei geral. ${ }^{7}$ Já no segundo caso, ele é, em linhas gerais,

Todo direito que o homem tem em virtude de sua natureza - de sua condição de pessoa -, ou seja, aquele conjunto de coisas suas, de direitos, que o homem tem por si mesmo e não por concessão dos Parlamentos, dos Governos ou da sociedade: sua vida, sua integridade física e moral, suas liberdades naturais, etc. (HERVADA, 2006, pp. 23 e 24)

Os direitos positivos, que são instituídos - postos - pelo homem, não podem ser estabelecidos de maneira ilimitada. O homem pode, através das leis e acordos, repartir as coisas, não obstante, essa repartição não pode contrariar a lei natural e o direito natural dela decorrente, pois, do contrário, seria injusta.

\footnotetext{
${ }^{6}$ Uma das implicações que advêm da fórmula clássica da justiça é a de que ela não consiste em repartir os bens entre as pessoas, mas em respeitar a repartição estabelecida, dando a cada pessoa aquilo que é dela. Assim sendo, deve-se partir do pressuposto de que as coisas estão repartidas e podem estar ou não sob o poder de seus titulares. A repartição das coisas (que podem ser corpóreas e incorpóreas) é verificável ao se analisar a própria realidade: as coisas estão atribuídas a um sujeito, mesmo nas sociedades mais coletivizadas, e como exemplifica Hervada, "pelo menos na alimentação, na vestimenta e no trabalho existe necessariamente alguma repartição” (HERVADA, 2008, p. 79).

7 "Como já foi dito, o direito ou o justo vem a ser uma obra ajustada a outrem, segundo certo modo de igualdade. Ora, isso pode realizar-se de duas maneiras: 1. Em virtude da natureza mesma da coisa. Por exemplo, se alguém dá tanto para receber tanto; isso se chama o direito natural. - 2. Por convenção ou comum acordo. Por exemplo, quando alguém se dá por satisfeito de receber tanto. O que se pode dar de dois modos: primeiro, por uma convenção particular, quando pessoas privadas firmam entre si um pacto; segundo, por uma convenção pública, quando todo o povo consente que algo seja tido como adequado ou proporcionado a outrem, ou assim o ordena o príncipe, que governa o povo e o representa. Isso se chama direito positivo. " (AQUINO, Summa Theologica, II-II, q. 57, a. 2, r.)
} 
Dessa questão, surgem as seguintes perguntas: se o direito natural tem como fundamento a própria natureza humana, quem pode dizer o que é direito natural ou não? $\mathrm{E}$ quem diz o que é lei natural? A resposta para tais perguntas é: o jurista. Da mesma forma que quem diz quais são as leis biológicas é o biólogo e que quem diz quais são as leis econômicas é o economista, quem diz o que é direito natural é o jurista (HERVADA, 2006, p. 158). Como já afirmado, a atividade do jurista consiste exatamente na iuris dictio, na declaração do direito, seja ele positivo ou natural.

\section{A IMPORTÂNCIA DAS VIRTUDES DA PRUDÊNCIA E DA JUSTIÇA NA ATIVIDADE DO JURISTA}

Como visto anteriormente, no âmbito de todas as suas ações é necessário que o homem seja aperfeiçoado pelas virtudes. Se assim não o for, ele decide com base em vários fatores: "por preconceitos, por interesses interesseiros, por impulso[s] egoísta[s], por inveja ou por qualquer outro vício"(LAUAND, 2003, p. 322).

No que tange às ações ligadas ao exercício de uma atividade profissional, as virtudes têm especial importância, pois "todo ofício tem uma utilidade, atende a uma necessidade social ou particular" (HERVADA, 2008, p. 57). Levando em consideração que através do desempenho de um ofício o homem pode realizar grandes contribuições para o bem comum, fica clara a necessidade de que na prática de sua profissão o indivíduo também realize boas escolhas e seja, para tanto, aperfeiçoado pelas virtudes.

Ora, não é suficiente que um profissional somente domine as técnicas relacionadas ao seu ofício para que ele o desempenhe bem. Por esse motivo, não é raro ver indivíduos que têm amplo conhecimento em sua área de atuação e que, ainda assim, são maus médicos, professores ou advogados, por exemplo. Se um profissional não for virtuoso, ele não realizará suas funções tendo em vista alcançar o bem comum, mas apenas intentará seus próprios interesses e agirá de forma a alcançá-los. Revela essa preocupação com o patrimônio moral do profissional o fato de que em grande parte dos cursos lecionados nas universidades há disciplinas relacionadas à ética no exercício da profissão (normalmente, denominada Deontologia, pois não pretender esgotar a conduta virtuosa, contentando-se com a sua manifestação exterior).

Em seu ofício, é essencial que o jurista realize boas escolhas: primeiramente devido à importância social de sua atividade, que "nasce no contexto das relações sociais diante da necessidade de que cada um tenha pacificamente em seu poder aquilo que lhe pertence" 
(HERVADA, 2008, p. 57); em segundo lugar porque seu ofício é discernir o justo, dizer o que é direito de cada um.

Se no desempenho de sua atividade o jurista não foi orientado pelas virtudes, seus apetites inferiores ou a falta de retidão de sua vontade poderão desviá-lo do cerne de seu ofício, que é dar a cada um o seu, e levá-lo a julgar tendo por base outros critérios, o que faria com que ele realizasse escolhas injustas.

De tal forma, sabendo que a razão indica ao indivíduo que atitude tomar e que a vontade o conduz a querer o que a razão determinou, quanto ao ofício do jurista o mesmo ocorre: a razão indica qual é o justo no caso concreto e a vontade o leva a querer dar ao sujeito o seu direito. No entanto, é necessário repetir: se o jurista não for aperfeiçoado pelas virtudes, não será capaz de dizer o justo de cada um. Por esse motivo, o jurista deve ter sua razão aperfeiçoada pela prudência e sua vontade aperfeiçoada pela justiça. Assim Hervada (2008, p. 58) explica:

Dentro do agir humano, a razão e a vontade têm missões complementares. Cabe à vontade o querer a ação; é próprio da razão saber realizar corretamente a ação. Por isso, a prudência dá a regra da ação e é a que guia a força da vontade. O agir jurídico não é uma exceção. Se a ação jurídica ou ação justa consiste em dar a cada um o seu, seu direito, o qual é obra da justiça - baseada na vontade -, o saber agir corretamente - saber dar a cada um o seu no momento e prazo adequados - é próprio da prudência jurídica ou jurisprudência. Em suma, como no restante do atuar humano, a atividade jurídica requer saber e querer, saber dar a cada um o seu e querer dá-lo. Querer é próprio da vontade justa, saber é próprio da razão prudente. A atividade jurídica é obra do homem justo e prudente.

É necessário frisar que, não sendo um moralista, ao analisar o caso concreto o jurista não observa a retidão moral de quem realiza a justiça, nem com que ânimo este dá ao próximo o que é dele, porque "seu objetivo é determinar a obra externa da justiça, sem entrar na intimidade do coração de quem age" (HERVADA, 2006, p. 95). No entanto, para realizar bem sua função (dizer o direito) é necessário que ele tenha suas potências aperfeiçoadas pelas virtudes. Em outras palavras, o jurista, no exercício de sua função, não se preocupa tanto com a retidão moral alheia; no entanto, é essencial que ele se preocupe com a própria.

Dentre as virtudes cardeais, aquelas que são mais importantes para o jurista no exercício de seu ofício são a prudência e a justiça. Na verdade, essas virtudes são a base do seu ofício (HERVADA, 2008). Ensina Hervada (2008, p. 58) que "a prudência é uma virtude intelectual ou dianoética, a virtude do correto agir moral, o que está relacionado com a justiça, que também é virtude moral". É possível perceber que no jurista, o direito e essas duas virtudes, estão intimamente ligados, pois, como já é sabido, o jurista é aquele que tem por ofício dizer o direito (iuris dictio), o qual é objeto da justiça; a justiça, por sua vez, consiste na 
vontade constante e perpétua de dar a cada um seu direito; e, por fim, a prudência torna possível o discernimento do direito. A respeito dessa ligação expõe Mauro de Medeiros Keller (2003, pp. 325 e 326):

Com efeito, faz-se mister, antes de todo o mais, considerar o direito como algo vinculado, necessariamente, ao conceito de Justiça. É pela mediação da Justiça que o direito reporta-se à prudência como capacidade mediante a qual se opera o seu achamento. Não há direito e o direito não se compreende senão no âmbito da Justiça, razão pela qual, a rigor, representa uma contradição a ideia de um direito injusto. Ora, uma vez que, identicamente, não há justiça sem prudência, tem-se que não pode haver direito, ou melhor, não pode haver descoberta ou achamento do direito que dispense a referência ao agir prudencial.

A atividade do jurista consiste, como já foi exposto, em uma ciência prática, pois, é um saber dirigido a um agir. A ele cabe, como aponta Hervada (2008, p. 63), "discernir e assinalar o seu de cada um para que seja dado a seu titular", indicando "o que o homem deve fazer para ser justo, para dar a cada um o seu, ou seja, para fazer a obra da justiça". Apesar de ser composto também de conhecimentos especulativos, "é um saber essencialmente prático, deve consistir em um hábito - habilidade ou aptidão - da razão prática pela qual possa chegar a conhecer - em cada caso - qual é o direito e como deve ser interpretada a lei" (HERVADA, 2006, p. 81). Ora, o hábito da potência intelectiva de saber agir corretamente constitui uma virtude - a virtude da prudência.

É preciso observar que, apesar de a atividade do jurista ter uma íntima relação com a justiça, esta não é sua virtude específica. Obviamente, para que ele realize bem suas funções, é essencial que o jurista ame a justiça, "pois, do contrário, dará ouvido à injustiça e substituirá a prudência do direito pela falsa prudência da injustiça" (HERVADA, 2008, p. 63). A justiça é pressuposto para a atividade do jurista, pois, além de saber o justo, é necessário que ele queira dá-lo a seu titular. Ora, se o querer é obra da vontade, é necessário que a vontade seja aperfeiçoada pela virtude da justiça. No entanto, o jurista não é o justo, mas o jurisprudente (HERVADA, 2008). Isso quer dizer que o jurista não dá a cada um o seu, mas indica aquilo que cabe a cada um.

No que tange à importância da virtude da prudência no ofício do jurista, Keller (2003, p. 328) coloca uma interessante objeção que pode ser levantada:

Se na realização da Justiça, que tem por objeto a obtenção do direito, em sentido estrito (dikáion) o que importa é o que objetivamente está determinado, não tendo qualquer relevância as boas disposições daquele que age, não há necessidade de recorrermos à prudência, pois a determinação deste direito, objetivo, poderia mais seguramente ser fixada a nível institucional, prévio e fundante da decisão daquele que age. Se o que importa é o objetivo, não o subjetivo, se é o justo em si, e não o bem de quem julga, para que se recorrer à prudência? Não é certo que muitas decisões justas são tomadas não porque quem as toma é virtuoso e prudente, mas porque teme as vol.09, nº. 03, Rio de Janeiro, 2016. pp. 
consequências para si de uma atuação em contrário?
E da seguinte maneira o referido jurista responde tais indagações:

Em verdade, convém salientar que a decisão justa, correta, não é justa porque é justo quem a toma, mas porque, prudentemente, prudencialmente, soube-se fixar o meio-termo. Ora, o justo (dikaion) é objetivo. Em si, tem um valor que não depende das intenções subjetivas de quem o realiza. Todavia, quem o realiza jamais poderá habitualmente acertá-lo sem as intenções retas, que condicionam o bom exercício da prudência. A institucionalização pode apontar, a esse respeito, para uma solução, mas não tem força para dispensar o julgador do esforço de almejar a consecução da Justiça, a descoberta do dikaion no concreto, e de forma habitual. (KELLER, 2003, p. 328)

Dessarte, levando em consideração que o justo é objetivo (não depende da intenção de quem o realiza), conclui-se que o jurista pode tomar uma decisão justa sem ser pessoalmente justo. No entanto, para conferir soluções justas com habitualidade, é necessário que o jurisprudente seja virtuoso, que tenha as virtudes da prudência e da justiça. As leis podem, nesse contexto, ajudar o jurista em sua atividade de dizer o direito; porém, a legislação não substitui as virtudes do jurista.

Outra objeção que pode ser levantada contra a fundamentação prudencial é a de que tal posição "estaria dando entrada ao absolutismo da decisão, a um anarquismo derivado de um certo situacionismo ético e jurídico" (KELLER, 2003, p. 329). No entanto, tal questionamento não procede, porquanto o jurisprudente baseia suas decisões nas normas universais, as quais aplica a cada caso singular. Sendo assim, o jurisprudente não julga tendo por base suas próprias convicções ou opiniões, mas, sendo aperfeiçoado em seu intelecto pela virtude da prudência, busca as normas universais e tem a docilidade de se deixar guiar por elas ao discernir o que é de cada um.

\section{A prudência, a justiça e as leis}

O conhecimento das leis positivas é deveras importante para a atividade jurídica, visto que elas também atribuem ao sujeito o que é dele. Como leciona Hervada (2006, p. 96), "se o jurista estuda as leis, faz isso porque elas têm uma estreita relação com o direito". No entanto, é preciso ter em mente que o direito - e não a lei - está no centro da atividade do jurista. Apenas saber a letra das leis não é suficiente para o exercício desse ofício, pois, mesmo que um indivíduo conheça todas as leis que compõem o ordenamento jurídico de um país, isso não o torna um jurista. Ora, qualquer pessoa que domine a técnica da leitura pode ler a letra da lei; porém, o jurista é aquele que a interpreta, e esta atividade "exige uma peculiar prudência, um tipo especial dessa virtude, que se chama prudência do direito; em latim, iuris prudentia, de onde vem a palavra em espanhol jurisprudencia" (HERVADA, 2006, p. 80). 
Por ser o titular da prudência do direito, o jurista, que é o perito em descobrir o seu de cada um, também é chamado de jurisprudente ou jurisperito. Assim sendo, quando um estudante ingressa na Faculdade de Direito para aprender o ofício de jurista, ele "não vai à Faculdade - principalmente - para aprender o texto das leis; vai para adquirir mentalidade jurídica, isto é, o hábito da jurisprudência, da prudência do direito" (HERVADA, 2006, p. 82).

A atividade interpretativa do jurisprudente não pode ser realizada de forma apenas literal, utilizando a máxima de que quando a lei diz algo, é esse algo e nada mais, ou, como disse Hervada, que é "pão, pão, queijo, queijo". Afinal, avisa o jurista espanhol,

[...] vamos lembrar quantos tipos, qualidades e variedades existem de pão e de queijo, e talvez assim se vislumbre que onde se diz queijo é preciso ter o tino de saber qual queijo convém servir, para que não se sirva aos amigos um queijo do mais comum no dia do casamento e um camembert da melhor qualidade em um dia sem especial importância, numa refeição informal. A oportunidade e o tino fazem parte da prudência. (HERVADA, 2006, p. 82)

Outrossim, a prudência jurídica também é imprescindível para o jurisperito no momento em que ele aplica as leis, visto que essa aplicação deve ser realizada de acordo com a realidade social. Certo é que, para que as leis sejam bem-sucedidas ao regular a vida social, ao mesmo tempo em que os cidadãos devem se adequar a elas, elas devem se adequar aos cidadãos. Como diz Hervada (2006, p. 107), “a realidade social é regulada pela lei, e, nesse sentido, é a vida social que se adapta à lei; mas, por outro lado, essa regulação deve ser feita de modo que a vida social se desenvolva de acordo com seu estado e suas condições". E ele exemplifica:

Um exemplo pode servir de esclarecimento. Para corrigir os pés chatos de uma criança é costume usar sapatos ortopédicos. É característica desses sapatos ter uma forma tal que, ao andar, exercem pressão sobre a planta do pé e vão curvando o osso correspondente até conseguir sua forma normal. A lei pode ser comparada a esses sapatos ortopédicos; sua função é regular, canalizar a realidade social e ir conformando-a de uma determinada forma. Assim como o sapato ortopédico dá forma ao pé, a lei deve dar forma à sociedade regulada. No entanto, não é menos certo que o sapato ortopédico deve se adequar ao pé. Se o paciente calça número 25 , não pode usar sapatos número 42 , por mais ortopédicos que sejam; além de fazê-lo parecer um palhaço, mais o prejudicariam que curariam. Assim também a lei deve estar de acordo com a situação própria da realidade social. (HERVADA, 2006, p. 107)

No momento em que uma lei é criada, deve-se ter em mente que as mudanças a serem implementadas devem ser feitas de maneira gradual. Assim o é porque "toda lei, ao ser cumprida, cria nos cidadãos os hábitos - os usos e costumes - correspondentes" (HERVADA, 2006, p. 103); no entanto, criar novos hábitos é algo que demanda tempo e esforço até que haja a adaptação da sociedade. Além disso, é preciso discernir se aquela sociedade pode adaptar-se 
àquela lei, e, também, de que forma aquela lei pode ser aplicada à sociedade. Nesse momento, é necessária a prudência do jurista:

O jurista deve ter a perspicácia de saber até onde se pode chegar na aplicação da lei, qual é o coeficiente de acomodação da realidade social para que, aplicando-se a lei, esta seja fator de ordem e progresso, e não de perturbação. Se chegasse a esse último caso, a lei deixaria de ser razoável e se transformaria em um fator espúrio da ordem social. (HERVADA, 2006, p. 105)

A forma como uma lei é interpretada e aplicada não pode ser imóvel, mas, se necessário, deve mudar no decorrer do tempo para se adequar às novas realidades sociais. É verdade que as leis promovem alterações na sociedade; no entanto, muitas vezes a realidade social muda mais rápido do que o ordenamento jurídico, fazendo com que ele, em alguns aspectos, se torne ultrapassado e não atenda bem às necessidades sociais.

Ao mesmo tempo, não é possível alterar as leis a todo momento - primeiro, porque o trâmite legislativo é bastante burocrático e demanda certo tempo; segundo, porque a solidez de um ordenamento jurídico e a sabedoria política dos povos pode ser demonstrada através da estabilidade de suas leis. Sendo assim, como é possível resolver essas questões e adaptar a lei à realidade? Segundo Hervada, o jurista, utilizando a prudência, deve realizar a interpretação progressiva das leis, através da qual estas "vão sendo aplicadas de acordo com a evolução da realidade social, permitindo que as mesmas leis sirvam ao bem da sociedade, sem defasagem entre lei e realidade" (HERVADA, 2006, p. 105).

A importância das virtudes da prudência e da justiça se estende, também, ao momento em que o jurista exerce sua função de dizer o que é direito natural e lei natural. Sendo o direito natural aquilo que, em si mesmo, é justo e está de acordo com os postulados naturais da reta razão (HERVADA, 2006), o jurista somente será capaz de discernir aquilo que é atribuído a cada um pela natureza humana se ele de fato quiser dar a cada um o seu. Outrossim, o jurisprudente não poderá dizer o direito se sua razão não estiver aperfeiçoada para discernir corretamente o seu de cada um. Ora, destarte, para que o jurista diga o que é direito natural, ele precisa ser orientado pela virtude que o aperfeiçoa em sua vontade (a justiça), tornando-o justo para que queira dar a cada um o seu, e pela virtude que o aperfeiçoa em seu intelecto (a prudência), tornando-o prudente para que saiba aquilo que deve dar a cada um.

\section{CONCLUSÃO}

Podemos concluir que o jurista, no exercício de seu ofício, além de possuir conhecimento jurídico, deve aperfeiçoar-se moralmente através da aquisição, ainda que inicial, das virtudes. Ora, se todos os indivíduos, para que realizem boas escolhas, precisam ser vol.09, n. 03, Rio de Janeiro, 2016. pp. 
aperfeiçoados em suas capacidades pelas virtudes, tanto mais o necessita o jurista, que tem como função discernir o justo. Se assim não o for, o jurista pode julgar sendo guiado não por uma reta razão do agir visando dar a cada um o que lhe é devido, mas conduzido por preconceitos, impulsos egoístas, dentre outros fatores que minam o alcance do bem comum buscado em sociedade.

É possível concluir, também, que o ofício do jurista não consiste simplesmente em dar aos indivíduos aquilo que as leis positivas determinam. Na verdade, a atividade do jurista consiste em dizer o direito de cada um em cada caso específico, o qual é atribuído a ele pelo direito natural ou pelo positivo. Para tanto, ele necessita ser aperfeiçoado pelas virtudes, para que tenha a razão reta a fim de saber o que é de cada um e para que sua vontade queira dar a cada um o seu. São necessárias a ele, portanto, as virtudes da prudência e da justiça especialmente.

\title{
THE IMPORTANCE OF THE VIRTUES OF PRUDENCE AND JUSTICE IN THE JURIST'S ACTIVITY
}

\begin{abstract}
The present study discoursed about the activity of the jurist according to the Classical Juridical Realism, which is based on the aristotelian-thomistic philosophy. It has the objective of demonstrating the importance of prudence (right reason in acting) and of justice (constant and perpetual will to render each person its due) - both cardinal virtues - when performing this function. In order to achieve the intended goal, a bibliographical research into doctrines of moral philosophy and philosophy of law was done. The reached conclusion is that besides having juridical knowledge, the jurist needs to improve morally.
\end{abstract}

Keywords: Jurist. Prudence. Justice.

\section{REFERÊNCIAS BIBLIOGRÁFICAS}

ABBÀ, Giuseppe. História crítica da filosofia moral. São Paulo: Instituto Brasileiro de Filosofia e Ciência "Raimundo Lúlio" (Ramon Llull), 2011.

AQUINO, Tomás de. As Virtudes Morais - Questões disputadas sobre a virtude - questão 1e 5. São Paulo: Ecclesiae, 2012.

AQUINO, Tomás de. Suma Teológica. Vol. VI: II ${ }^{a}$ seção da II $^{a}$ parte. São Paulo: Edições Loyola, 2001. 
FAITANIN, Paulo Sérgio. "A Gnosiologia Tomista". S/d a. Disponível em: <http://www.aquinate.net/portal/Tomismo/Filosofia/a-gnosiologia-tomista.php> Acesso em: $07 / 01 / 2015$

FAITANIN, Paulo Sérgio. "A Psicologia Tomista". S/d b. Disponível em: <http://www.aquinate.net/portal/Tomismo/Filosofia/a-psicologia-tomista.php> Acesso em: $07 / 01 / 2015$

HERVADA, Javier. Lições propedêuticas de filosofia do direito. São Paulo: WMF Martins Fontes, 2008.

HERVADA, Javier. O que é o direito? A moderna resposta do realismo jurídico: uma introdução ao direito. São Paulo: WMF Martins Fontes, 2006.

KELLER, Mauro de Medeiros. "Reflexões sobre o fundamento prudencial da atividade jurídica”. Revista Brasileira de Direito Constitucional, n. 2, pp. 325-331, jul./dez., 2003. Disponível em: <http://esdc.com.br/seer/index.php/rbdc/article/view/55>. Acesso em: 18 jun. 2015.

LAUAND, Luis Jean. "A arte de decidir: a virtude da prudentia". Revista Brasileira de Direito Constitucional, n. 2, pp. 315-324, jul./dez., 2003. Disponível em: <http://esdc.com.br/seer/index.php/rbdc/article/ view/54>. Acesso em: 18 jun. 2015.

PÊCEGO, Daniel Nunes. "A lei e a justiça na Suma Teológica". Revista Aquinate, $\mathrm{n}^{\circ} 6$, 2008a, pp. 160-178.

Disponível em: <http://www.aquinate.net/revista/edicao_atual/Artigos/06/Artigo\%209Pecego.pdf $>$. Acesso em: 01/11/2014.

PÊCEGO, Daniel Nunes. "O direito na Suma Teológica". Revista Aquinate, n 7, 2008b, pp. $92-113$ em: <http://www.aquinate.net/revista/edicao_atual/Artigos/07/Artigo\%206-Pecego.pdf>. Acesso em: 01 nov. 2014.

Trabalho enviado em 10 de julho de 2016.

Aceito em 17 de julho de 2016. 